
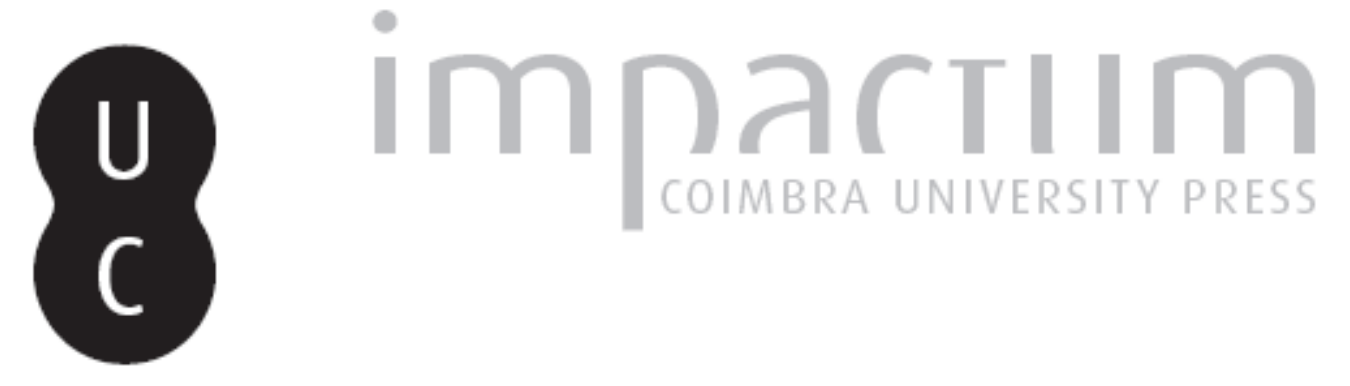

\title{
A política administrativa de Tutmés III no levante
}

Autor(es): Martins, Daniela

Publicado por: Centro de História da Universidade de Lisboa

URL persistente:

URI:http://hdl.handle.net/10316.2/32978

DOI:

DOI:http://dx.doi.org/10.14195/0871-9527_22_5

Accessed : $\quad$ 26-Apr-2023 02:17:10

A navegação consulta e descarregamento dos títulos inseridos nas Bibliotecas Digitais UC Digitalis, UC Pombalina e UC Impactum, pressupõem a aceitação plena e sem reservas dos Termos e Condições de Uso destas Bibliotecas Digitais, disponíveis em https://digitalis.uc.pt/pt-pt/termos.

Conforme exposto nos referidos Termos e Condições de Uso, o descarregamento de títulos de acesso restrito requer uma licença válida de autorização devendo o utilizador aceder ao(s) documento(s) a partir de um endereço de IP da instituição detentora da supramencionada licença.

Ao utilizador é apenas permitido o descarregamento para uso pessoal, pelo que o emprego do(s) título(s) descarregado(s) para outro fim, designadamente comercial, carece de autorização do respetivo autor ou editor da obra.

Na medida em que todas as obras da UC Digitalis se encontram protegidas pelo Código do Direito de Autor e Direitos Conexos e demais legislação aplicável, toda a cópia, parcial ou total, deste documento, nos casos em que é legalmente admitida, deverá conter ou fazer-se acompanhar por este aviso.

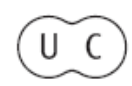



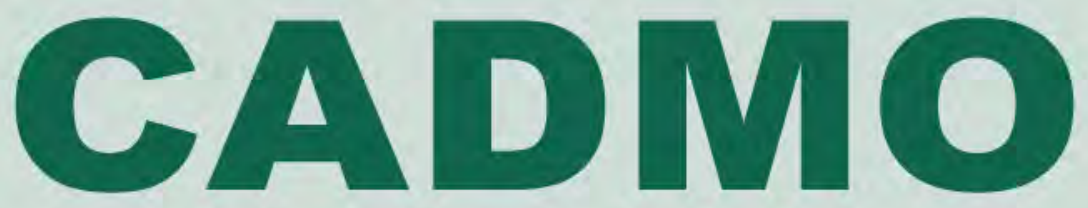

Revista de História Antiga

\author{
Centro de História \\ da Universidade de Lisboa
}

\title{
22
}

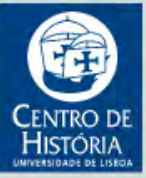

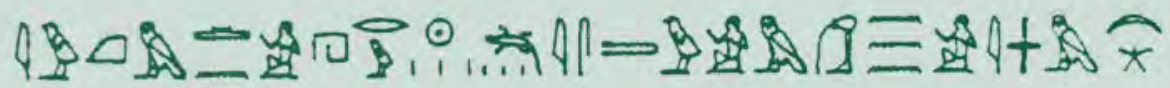

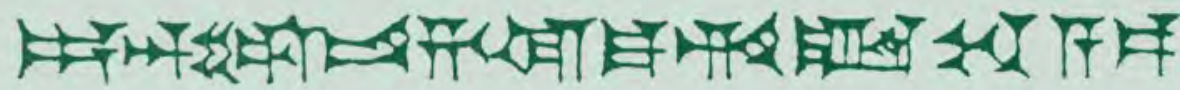
MHNIN AEI $\Delta \mathrm{E} \Theta \mathrm{EA} \Pi \mathrm{\Pi H} \Lambda \mathrm{HIA} \Delta \mathrm{E} \Omega$ 


\title{
A POLÍTICA ADMINISTRATIVA DE TUTMÉS III NO LEVANTE
}

DANIELA MARTINS

Universidade de Lisboa danielaffmartins@gmail.com

\section{Resumo}

No reinado de Tutmés III, o Egipto criou uma nova dinâmica sobre a Ásia. Seguindo-se às campanhas militares, o território levantino foi organizado política e militarmente, de forma a garantir um domínio administrativo sobre o espaço conquistado. Este novo modelo será amplamente desenvolvido ao longo de todo o Império Novo.

Palavras-chave: Tutmés III; Síria-Palestina; administração «imperial».

\begin{abstract}
In the reign of Thutmose III, Egypt created a new dynamic in Asia. Following the military campaigns, the Levantine territory was political and military organized, to guarantee an administrative control over the conquered space. This new model will be developed in all New Kingdom.
\end{abstract}

Key-words: Thutmose III; Syria-Palestine; «imperial» administration.

A abertura ao estrangeiro que o Império Novo cria é um dos temas que mais curiosidade oferece, pela sua aparente contradição na relação com esses mundos, pois ainda que dinâmica a sociedade antiga sempre se mostrou isolada naquilo que são as suas convicções relativas ao seu povo e à sua cultura, julgando-se sempre superior aos seus contempo- 
râneos. Verificamos, no que respeita aos Egípcios, que ainda que desde os seus primórdios históricos tenha convivido com o "estrangeiro", nunca deixou de mostrar a sua suprema convicção na superioridade das Duas Terras em relação a todo o resto. Esse pensamento, muito marcado até por uma própria configuração geográfica, levou a que a abordagem ao «estrangeiro» fosse, de certo modo, dúbia: por um lado, um mundo de «barbárie» contrário aos valores maéticos e culturais egípcios; por outro, apresentando imensos recursos naturais e materiais fulcrais para assegurar a sua própria cultura, o culto aos deuses e o seu próprio modo de vida. Maet reinava única e somente em Kemet, e esta luta entre o caos e a ordem, que desde cedo se tornou uma das matrizes base do pensamento e da moral egípcias, parece ser muito mais vasta do que os seus próprios limites geográficos. Será pois o interesse económico e comercial em várias zonas ou entrepostos fora do Egipto que ditará muitas vezes a actuação política, que culminará, no Império Novo, com a conquista territorial do Corredor sírio-palestiniano¹.

\section{Acção militar na Síria-Palestina: causa ou consequência?}

Tradicionalmente, a expulsão dos Hicsos é vista como uma mudança na política egípcia face aos estrangeiros. De facto, a maioria dos autores vislumbra este período de domínio estrangeiro a norte como um momento estruturante e impulsionador das campanhas militares que se levam a cabo no Império Novo, e também o assumem como uma experiência traumatizante para o povo egípcio.

Contudo, serão estes avanços militares e esta nova «política externa» uma consequência da presença dos Hicsos? Ou, por outro lado, serão impulsionadas devido à disputa pelo Levante com as novas potências emergentes que punham em perigo o tradicional domínio egípcio sobre a zona?

\subsection{O Egipto e os «outros»}

Parece-nos claro, à semelhança da geral bibliografia no âmbito da Egiptologia, que a presença dos Hicsos em solo egípcio fora um momento crucial, criando uma situação nova para os próprios Egípcios, que nunca se haviam visto dominados por estrangeiros. 
Contudo, sabemos que a relação das Duas Terras com entidades externas era frequente desde os tempos mais remotos, pois desde cedo as actividades comerciais assim o ditaram, a que não obstou os Egípcios, à semelhança de todos os outros povos da época, se considerarem superiores aos seus contemporâneos. De qualquer maneira, não podemos passar à margem de que, desde o Império Antigo, os Egípcios desenvolveram uma estratégia de defesa, que procurava manter seguras as fronteiras de Kemet, sobretudo a sul e a este. Por isso é que se constroem os «Muros do Rei» e outras fortalezas na zona este, com guarnições ${ }^{2}$. Atrever-me-ia a dizer, aliás, que a zona este sempre foi alvo de maior preocupação estratégica e militar do que o Sul, a Núbia, pelas dificuldades que podia criar. Através de fontes como a História de Sinuhe, datável do Império Médio, denotamos não só que a influência egípcia é mais ampla do que a sua geografia como também existe já a ideia de uma fronteira ${ }^{3}$. Não obstante, é nas Profecias de Neferti que encontramos uma frase que ainda que relacionada com a questão do Primeiro Período Intermédio, pensamos ser bastante elucidativa do pensamento egípcio sobre o que é exterior à sua realidade geográfica:

"Construir-se-ão os Muros do Rei, não permitindo que os Asiáticos desçam ao Egipto (...) Maet regressará ao seu lugar e o mal para a parte exterior.» ${ }^{4}$

Fica claro que, do ponto de vista egípcio, e pelo menos na sua concepção teórica, o espaço externo ao Egipto é uma realidade caótica, pois parte de uma noção de alteridade ${ }^{5}$ da sua cultura, do seu modo de vida e dos seus próprios deuses ${ }^{6}$. Ainda assim, pelo menos numa dimensão prática, pensamos que há uma consciência de que estes povos não são marginais. Todos estes elementos acabam por conduzir a uma discussão teórica relativa a conceitos, isto é, podemos falar, quando nos reportamos às civilizações pré-clássicas, de uma concepção por parte desses povos de uma oposição de civilização versus barbárie? Ou, por outro lado, será mais adequado falar num antagonismo entre caos e ordem? Quando fazemos uma leitura atenta sobre estas ideias naquilo que a historiografia produziu, verificamos que as opiniões não são consensuais, ainda que não haja uma discussão, no verdadeiro sentido do termo, sobre esta problemática. Na nossa opinião, e em termos gerais, essa maneira de ver o «outro» é sobretudo assente na oposição de caos e ordem, uma ordem que reside nas Duas Terras, e um caos, pelo menos aparente, que 
é confinado a todo e qualquer espaço fora da sua geografia. Pensamos que os conceitos de civilização e barbárie, tipicamente clássicos, não se adequam tanto às civilizações que as antecedem. De uma maneira mais específica, essa noção de incivilizado poderá ser melhor aplicada a beduínos, nómadas, e não tanto às outras potências da época. Mas, não menos interessante será também pensar como é que isto é aplicado e se correlaciona numa política «imperial», como a existiu sobretudo no Império Novo. Zainab Bahrani, que estudou esta dicotomia aplicada à Mesopotâmia, defende que o discurso do "outro" se transforma num motivo legitimador para a guerra e para a conquista de território7. Será que podemos usar o mesmo princípio para o contexto das Duas Terras?

O problema (se é que podemos falar num problema) dos estrangeiros e da sua relação com os outros parece ter, numa dimensão prática, um lado absolutamente cooperativo, excepto em caso de confronto bélico directo, por um lado pelas necessidades económicas e comerciais da Síria-Palestina e, também, no plano político, com o firmar de acordos e tratados de não-agressão em função da afirmação e aumento de poderio de outras potências.

\subsection{As campanhas militares: defesa das fronteiras ou de interesses?}

Terão sido, por um lado, as alterações climatéricas que ocorreram no Próximo Oriente Antigo e no Norte de África, em finais do Império Antigo que, aliados à fragilidade política verificada por essa altura no faraonato egípcio que tiveram como consequência não só um desenraizamento de populações como, por outro, deu espaço a um estabelecimento lento e progressivo de populações no Egipto ${ }^{8}$. A penetração destas populações é essencialmente no Norte, portanto no Baixo Egipto e fundamentalmente no Delta. Neste contexto, as vagas de imigrantes aumentam e progrediam a sul, na procura de trabalho nas grandes capitais da época, Mênfis e Iti-taui ${ }^{9}$. Mas é chegados ao Segundo Período Intermédio que podemos pôr ou não em causa o facto de os Hicsos serem populações belicosas. Os Hicsos poderão ser a massa de estrangeiros que se foi instalando progressiva e continuamente no Delta Oriental ou, por outro lado, serão um grupo guerreiro que se apoderou dessa zona? Há autores que defendem ambas as opções e não é nossa intenção entrar nesta discussão, uma vez que não são esses os nossos propósitos. Contudo, pensamos tratar-se de uma 
população que se vai instalando desde o Primeiro Período Intermediário e cujos níveis de imigração poderão ter sido mais intensos durante os finais do Império Médio e Segundo Período Intermediário. Pensamos também que se trata de uma população de carácter heterogéneo, congregando nómadas do norte do $\operatorname{Sinai}^{10}$ e populações da Palestina ${ }^{11}$. Para além disto, está associada a estas comunidades uma importante dinâmica comercial exclusiva com a sua zona de origem, criando-se, segundo alguns, um hiato comercial com a Síria ${ }^{12}$. Devemos acrescentar que estas trocas foram estabelecidas não por vias terrestres mas sim marítimas ${ }^{13}$. Devemos ter em conta que, inicialmente, os asiáticos que se dirigiram ao Egipto integraram-se ou procuraram integrar-se na cultura egípcia, mas a fragilidade do faraonato deu-Ihes oportunidades políticas, criando então um nicho administrativo seu no Delta e, já nessa fase, mantendo a sua própria cultura ${ }^{14}$.

De qualquer modo, e para além da memória funesta que esta experiência hicsa vai criar na mentalidade egípcia, funcionando como um dos vectores-base que conduzem a uma política imperial, tratar-se-á de empurrar o inimigo para a sua própria terra e não simplesmente libertar as fronteiras egípcias da sua presença, numa clara demostração de força e poderio militar. Por este motivo, alguns autores falam de um «momento de acentuado nacionalismo ${ }^{15}$, mas aquilo que nos parece claro é que se trata, essencialmente, de uma recusa tebana ao seu estatuto de «vassala» do poder do Norte, aliada aos condicionalismos económicos, e propiciada, em grande medida, pela disponibilidade de um exército que havia sido progressivamente organizado ${ }^{16}$.

Não obstante, o avanço para a Ásia tomará um carácter diferencial com Tutmés III. Até então, os faraós egípcios centraram-se sobretudo em excursões militares e tomada de cidades. Esta situação vem pôr em questão um problema de fundo, isto é, terá criado o Egipto uma hegemonia política e militar sobre o território da Síria-Palestina? Como sabemos, este espaço era bastante apetecível pois era uma área de grande produção de azeite, vinho e trigo, com bastantes recursos de madeira, metais preciosos e escravos, era local de confluência de rotas comerciais e um ponto de ligação daquele(s) mundo(s), sendo por isso uma região altamente disputada pelas potências da época, Egipto, Mitanni e Hatti ${ }^{17}$.

No entanto, se analisarmos, ainda que de forma breve, o «sistema mundo» desta época histórica, verificamos que se atribui para o período de 1500-1470 a. C., a existência de um sistema multipolar (com mais 
de três grandes poderes), onde se destacam o Egipto, Hatti, Mitanni, Babilónia e Kizzuwadna ${ }^{18}$. Estamos a falar, em termos da cronologia egípcia, do reinado de Tutmés I em diante, até Hatchepsut. Durante este período, temos as incursões militares sobre a Ásia de Tutmés I, que são esporádicas, e durante as quais o faraó terá chegado ao Eufrates, assunto que, aliás, ainda suscita debate historiográfico ${ }^{19}$. O Egipto só se torna hegemónico, segundo David Wilkinson, quando os senhores da guerra são liderados por uma única potência suserana, o que, segundo o autor, se dá cerca de 1380 a. C., no reinado de Amen-hotep III. Do nosso ponto de vista, não podemos falar de uma hegemonia egípcia, pois o domínio do Levante, e em particular o da Síria, sempre foi altamente disputado e frágil, tendo em consideração os fortes laços que ligavam estas cidades aos poderes do Norte, mostrando grande resistência ao controlo egípcio.

Em suma, nem o Egipto era uma potência hegemónica nem os seus reis. Tinha, isso é certo, um papel fundamental, na medida em que se assumia como uma das maiores potências do mundo em questão, mas existiam outras grandes forças. Portanto, não podemos ver única e somente as campanhas militares egípcias do lado do Egipto, pois estamos entre um equilíbrio de poderes e não perante a hegemonia de um reino sobre os outros.

Em suma, o avanço militar para a Síria-Palestina apresenta-se tanto como causa como consequência. É uma resposta ao domínio hicso, resposta essa que procura afastar o estrangeiro o máximo possível das suas fronteiras, daí que o procure dissuadir, através de incursões militares, procurando também abrir cada vez mais as rotas que eram vitais ao Egipto. Por outro lado, tem na sua base um objectivo concreto, o da disputa da zona e dos interesses comerciais que Ihe estão subjacentes. No fundo, a expulsão dos Hicsos abriu caminho a uma política claramente ofensiva, centralizadora, imperial. Quebra-se a linha de um equilíbrio aparente, já que o Egipto tinha uma posição de destaque nesse comércio, e passa-se a um controlo efectivo daquela zona, o que mais tarde levará a que as zonas dominadas se tentem coligar com potências inimigas do Egipto.

E isto porque, como já mencionámos, a área se reveste de grande importância económica, na medida em que é uma região produtora e possuí grandes recursos, mas também por ser, como tantas vezes designamos, um corredor, um centro de passagem, de ligação entre as potências da época e de várias zonas do Médio Oriente Antigo entre as 
quais se estabeleciam importantes rotas comerciais, interligando estes mundos. É por esse motivo que Graciela Gestoso Singer apelida esta zona de «periferia disputada» por ser ao mesmo tempo uma «periferia produtiva e estratégica» ${ }^{20}$. Note-se que, pela própria terminologia usada, está subjacente a ideia de que o espaço nunca foi incorporado pelo Egipto, isto é, que nunca se pretendeu fazer com que o Levante fosse parte integrante das Duas Terras, mas sim apenas uma ramificação do mesmo, tal qual como a Núbia, que embora egipcianizada desde os tempos do Império Médio, nunca foi parte de Kemet, sendo antes uma dependência dele.

Em jeito de síntese, podemos dizer que os primeiros faraós da XVIII dinastia lideraram acções punitivas, das quais resultaram espólio e cativos, e não tiveram uma «preocupação» de ocupar permanentemente o espaço, até porque até ao reinado de Tutmés II ainda havia um grande esforço no restabelecer o controlo egípcio sobre a Núbia. Com Tutmés III, consolidam-se as fronteiras alcançadas de forma permanente, e organizam-se esses territórios, alterando-se pois a relação entre o Egipto e a Síria Palestina, com o estabelecimento de uma estrutura de governo na Ásia ${ }^{21}$, a qual procuraremos interpretar.

\section{Manutenção do espaço: estratégias de domínio}

A criação de uma estrutura de governo na Ásia é, do nosso ponto de vista, uma das marcas mais visíveis de como os Egípcios eram um povo prático e que se adaptava em diversas circunstâncias. Para percebermos como é inovadora e para compreendermos como estes lidaram com uma realidade distinta teremos, inevitavelmente, que olhar para a Núbia, a qual o Império Médio egipcianizou e que desde então se manteve sob o controlo das Duas Terras. De facto, as realidades históricas da Síria-Palestina e da Núbia são completamente diversas. Se a primeira tem um aglomerado de povos com uma estrutura definida, com as suas tradições e com a sua autonomia, a Núbia estava, no fundo, mergulhada a sul de toda a civilização da época, mantendo apenas contacto com os Egípcios, que eram sobre eles a cultura dominante. Perante este desequilíbrio entre as duas regiões, os Egípcios tiveram que adoptar para a Ásia uma estratégia de governo completamente distinta da usada para a Núbia. Não obstante, as estruturas que usaram no Sul são elucidativas, do ponto de 
vista estratégico e prático, de como era feita a imposição do seu poder e das maneiras para o controlar. No que respeita ao Levante, a situação é distinta, já que tiveram que criar uma malha governativa que se adaptou às diferentes regiões e cidades, de uma maneira muito própria, uma vez que se lidava com realidades concretas, particulares, ao longo deste grande terreno. Portanto, estamos perante o desenhar de uma estratégia político-administrativa e de controlo militar completamente nova.

Será fundamental, de qualquer modo, sublinhar que os exércitos com os quais Tutmés III vai combater nesta zona são exércitos profissionais, comandados por uma aristocracia militar e providos de um moderno equipamento ${ }^{22}$. Não menos importante é termos em linha de conta que os egípcios "não jogavam em casa», isto é, os adversários tinham, obviamente, vantagens sobre estes, quanto mais não seja pelo apoio logístico e de abastecimento de que dispunham ${ }^{23}$.

\subsection{Controlo territorial e político}

Falar de controlo territorial egípcio sobre a Síria-Palestina é falar, sem dúvida, de um confronto com aquela potência que desafiava o poder egípcio sobre a região, o Mitanni. Depois do reinado de Hatchepsut, cabia a Tutmés III empreender esforços na Ásia, esforços esses que haviam sido iniciados pelos fundadores da dinastia, e que levaram, ao que se supõe, o seu avô Tutmés I a terras nunca antes atingidas militarmente, o Eufrates. Tutmés III pretendeu, de alguma maneira, corrigir a inactividade militar nesta zona durante o reinado da sua tia-madrasta. De facto, numa primeira leitura, podemos deduzir que Hatchepsut não se dedicou, como era tradição dinástica, às expedições militares, o que poderá ter dado alento a estes povos, que vislumbraram uma oportunidade de ampliar a sua esfera de domínio e, como sugerem alguns autores, atreveram-se pensar invadir o Egipto. Na opinião de Richard Gabriel, se esse não fosse o objectivo, não se perceberia como é que trinta e um líderes de diferentes reinos, entre os quais se inclui o Norte da Síria e o Mitanni, se unissem militarmente ${ }^{24}$. Era, sem dúvida, a luta de influências, a luta pelo domínio do Levante. Desse modo, será fácil compreender porque é que chegado definitivamente ao poder único Tutmés III declare, nos seus Anais, que "desde lerasa até aos confins da terra rebelaram-se contra sua majestade ${ }^{25}$. Vencer os asiáticos que se haviam coligado contra 0 
rei egípcio era vital e prioritário. Contudo, se os militares tiveram pouca acção no reinado da faraó, não será menos importante sublinhar como esse período de paz fora fundamental para instruir o jovem Tutmés, sobretudo no campo militar, relembrando os feitos dos antecessores. Também importante será nomear, entre outras, a expedição a Punt, bem documentada nos baixos-relevos de Deir el-Bahari e cujo interesse, neste contexto, pauta-se essencialmente pelo uso dos militares e de barcos que atestam uma construção naval eficiente que permitia aos Egípcios fazer navegações de grande distância com uma capacidade de transporte de grande escala ${ }^{26}$, algo que será fundamental para Tutmés III.

Partimos do princípio que a inactividade militar de Hatchepsut abriu caminho ao alargar da influência do Mitanni, reino esse que ampliava a sua área de acção política por esta altura, de tal forma que estabelece o seu domínio sobre a Assíria e amplia a sua esfera de influência na Síria ${ }^{27}$. Por volta de 1480 a. C., o nome do rei mitânio, Paratarna, aparecia em Qatna e Ugarit ${ }^{28}$. Assim, quando Tutmés III sobe definitivamente ao trono, põe esta situação como prioritária, e vai mais longe do que algum faraó alguma vez tinha ido. A modernização do exército e a definição de uma nova doutrina no campo militar, que assentava na criação de uma "classe» específica para o efeito, ou seja, uma profissionalização das actividades de guerra, foram passos fundamentais para que o Egipto deixasse de ser estrategicamente defensivo e passasse a uma acção ofensiva clara, com efeitos concretos, que se pautava pela subordinação militar e política das cidades-estado de Canaã e da Síria ${ }^{29}$.

«[Ano 23], primeiro mês de Chemu, dia 5. Marcha deste lugar valentemente, [vitoriosamente], poderosamente e legitimamente, para derrotar aquele maldito inimigo, para expandir as fronteiras do Egipto, pois o seu pai Amon-Ré tinha ordenado [...] a vitória e sua conquista.»30

Não deixa de ser curioso reparar nas palavras que registam os Anais: legitimamente, pela rebelia dos estrangeiros; e para expandir as fronteiras do Egipto, leia-se, para expandir o controlo egípcio.

As campanhas empreendidas por Tutmés III podem ser divididas em cinco grupos de acção ${ }^{31}$ : em primeiro, desbaratar a coligação em Meguido; em segundo, as campanhas em Canaã; em terceiro, as campanhas na costa do Líbano; em quarto, a campanha no Eufrates; e por último as campanhas contra a insurreição. Não é, porém, nosso objectivo, aprofundar neste estudo as campanhas militares concretamente, mas 
sim as consequências que as vitórias do faraó acarretam, o domínio territorial e político. Como escreve Claire Lalouette, Tutmés III não fora só um grande militar, mas foi também um administrador lúcido, aquele que criou na verdade o império egípcio ${ }^{32}$.

Será pois nesse assunto em concreto que deteremos a nossa atenção.

\section{a) Capitais administrativas}

O vasto espaço da Síria-Palestina, para ser administrado, precisava de centros concretos, através dos quais se pudesse manter um controlo político claro, e que abarcasse ou conseguisse englobar toda a área conquistada. Desta forma, o Egipto criou uma maior rentabilização política e económica sobre a zona, como atestam os Anais de Tutmés III e as Cartas de Amarna. Como sublinha Singer, as Cartas de Amarna são a principal fonte para compreender a organização administrativa egípcia na Síria-Palestina e as técnicas de dominação usadas. Ainda que posteriores ao reinado de Tutmés III elas deixam-nos adivinhar as bases de toda essa estrutura que neste reinado é criada ${ }^{33}$.

Após Tutmés III o Egipto organizou o Levante em três grandes áreas: Amurru, na Síria Central, que era administrada a partir de Șumur; a zona da Síria Meridional, que era governada a partir de Kumidi; e por último a zona de Canaã, que era controlada a partir de Gaza ${ }^{34}$. Estes distritos eram governados pelo «superintendente dos países estrangeiros» que era, geralmente, um egípcio ${ }^{35}$. Os governadores tinham que lidar e se ocupar de diferentes tarefas, que passavam pelo recolher de tributos, garantir o aprovisionamento de bens ao exército e evitar distúrbios entre os locais, assim como supervisionar a actividade dos chefes e príncipes da região ${ }^{36}$. No reinado de Tutmés III, havia apenas um governador, o general Djehuti, seguindo-se depois Amenmés ${ }^{37}$. O general Djehuti é bem conhecido da literatura egípcia por ser o protagonista de uma das estórias populares do Império Novo, a tomada de Ipu, ou Jaffa, importante centro para a administração egípcia, já que aí se colocara uma guarnição militar ${ }^{38}$. Mas quem é este Djehuti? Será Djehuti, escriba de Hatchepsut, cujo túmulo foi recentemente escavado por uma equipa de arqueólogos espanhóis, liderada por José Manuel Galán? As inscrições provenientes do túmulo são curiosas. Na sua autobiografia, aparece-nos, à cabeça, a referência aos reis, aparecendo em primeiro Hatchepsut e depois uma menção a Tutmés III. Nesta, Djehuti sublinha o seu papel de funcionário competente, que supervisiona os trabalhos para a casa real e para os 
templos «porque ela (Hatchepsut) considerava que eu era eficaz» ${ }^{39}$. Na inscrição funerária, aparece a menção primeiro a Tutmés III e depois a Hatchepsut, o que poderá ser indício de que, por esta altura, a faraó já tivesse falecido. Contudo, as inscrições são do mesmo teor, revelando que Djehuti é um escriba. Portanto, estamos claramente perante uma outra pessoa. Em 1988, Christine Lilyquist fez um estudo muito interessante relativo a peças pertencentes a Djehuti hoje no Metropolitan Museum of Art. Aí sim, é nos dado a conhecer o importante general de Tutmés III, cujo nome e titulatura estão gravados em várias peças. No entanto, denota-se, também aqui, a confusão entre os dois Djehuti, o escriba e o general ${ }^{40}$, já que são da mesma época e ambos tiveram importantes cargos.

Para além disto, os governadores estavam encarregues de supervisionar as actividades dos príncipes locais. O poder destes funcionários egípcios era limitado, até pela própria dimensão do terreno que tinham que controlar, mas talvez mais importante do que isso, é o facto das estruturas políticas desta zona serem uma realidade já bem definida, o que levou a que estas fossem estrategicamente mantidas, pois de outro modo seria impossível o Egipto dominar a zona. Depondo aqueles que Ihe tinham feito frente, Tutmés III conduziu-os ao Egipto como prisioneiros de guerra, designando outro príncipe para o seu lugar, que lhe fizesse um juramento de lealdade. Em contrapartida o faraó concedia-Ihes o alento da vida. Além disso, os filhos dos príncipes eram conduzidos ao Egipto para serem educados no kap ${ }^{(41)}$, instituição que se ocupava de instruir a elite, e assim, egipcianizados, seriam importantes trunfos no domínio da Síria-Palestina. Tornando-os pois vassalos, o rei poderia controlar os novos territórios do ponto de vista territorial e político. Não menos importante será também dizer que, entre os príncipes designados, havia, naturalmente, venalidade dos cargos, isto é, a transmissão de cargos de pais para filhos, a menos que estes se rebelassem contra o faraó.

Entre as funções que estes príncipes locais desempenhavam estava a protecção das cidades do rei, e o reunir de trabalhadores para a corveia a prestar ao rei egípcio, que passava pelo cultivo da área circundante às cidades guarnição. O grão obtido tanto era armazenado nos celeiros reais situados junto às guarnições como nas cidades portuárias. O objectivo era, sobretudo, criar uma fonte de abastecimento para as tropas que guarneciam alguns pontos nevrálgicos e também para o exército do rei em campanha ${ }^{42}$ : 
"Os campos de cultivo foram convertidos em parcelas, as quais foram atribuídas aos agentes do palácio - vida, prosperidade e saúde! - para recolher a sua colheita. Relação da colheita que sua majestade trouxe das parcelas de Meguido: 207.300 sacos de trigo, além do que se cortou ao passo da tropa de sua majestade $[\ldots]$ \% 43

Muitas vezes, os príncipes locais tinham à sua disposição agentes que ajudavam a controlar as tarefas agrícolas. Singer adianta que há uma grande probabilidade destes terem recebido terras pelas funções exercidas. De qualquer maneira, o tributo que estes prestavam ao Egipto era mais vasto, incluindo gado ${ }^{44}$, matérias-primas e produtos manufacturados ${ }^{45}$. Isto é bastante visível nos Anais de Tutmés III, que nos dão amplas informações, e onde também se torna muito clara a importância da zona como entreposto comercial, onde afluem vários produtos de todo o Médio Oriente.

Durante as suas deslocações em campanha, o rei tinha ao seu dispor «palácios» ${ }^{46}$ que eram preparados para a sua estadia por um funcionário egípcio encarregado dessa função, como foi o caso de Intef no reinado de Tutmés: «(...) e quando o meu senhor chegava em paz, eu lhe dizia: "eu o preparei, eu o equipei com tudo o que se pode desejar numa terra estrangeira, melhor do que um acampamento no Egipto, as suas (diferentes) áreas organizadas, [apuradas], seguras e separadas, e (cada) dependência com o seu guardião" " ${ }^{47}$. Havia ainda templos dedicados a divindades egípcias, como forma de amparar religiosamente os egípcios em funções no exterior como também, de aproximar os estrangeiros à ordem egípcia, à sua devoção, fazendo com que estes compreendessem quem são os verdadeiros e únicos deuses, ainda que não forçosamente ${ }^{48}$.

O governador e os príncipes contavam ainda com o apoio de mensageiros, que eram responsáveis por manter a comunicação entre o Levante e a corte egípcia. Entre as suas funções estava o entregar de correspondência diplomática, comunicar mensagens orais, funcionar muitas vezes como intérpretes, levar presentes para o rei, levar para o Egipto as princesas estrangeiras oferecidas ao faraó, recolher o tributo para o monarca egípcio e informar sobre a situação política dos países estrangeiros ${ }^{49}$.

\section{b) Guarnições}

A presença de um alto funcionário egípcio era fundamental, mas a sua autoridade seria posta em causa se não houvesse no terreno a presença constante de um grupo de militares, prontos a intervir em caso de rebelião. 
Estar no terreno significava, muito mais do que a sua própria acção concreta, marcar presença, dissuadindo potenciais instigadores de revolta, até mesmo entre as potências estrangeiras. Dizemos isto porque o número de soldados que integravam cada guarnição era bastante reduzido, oscilando entre os 20 a 100 homens $^{50}$. Além disso, estes números dão ainda a entender que ficava bastante caro manter militares na Síria-Palestina, daí serem em baixo número. Estavam, diria, de uma forma preventiva, e quando as coisas se complicavam, o grosso do exército deslocava-se desde o Egipto para resolver eventuais situações de turbulência. É por este motivo que podemos dizer que havia dois tipos de exército, um de campanha, e outro de guarnição, ao dispor do governador e príncipes locais ${ }^{51}$. Estas guarnições estavam situadas em pontos estratégicos, de modo a controlar a vasta área da Síria-Palestina: Ugarit, Biblos, Șumur, Ullaza ${ }^{52}$, Takhchi, Kumidi, Jerusalém, Gaza ${ }^{53}$, Jaffa, Beth Shean ${ }^{54}$ e Yeno'am, algumas das quais já funcionavam no reinado de Tutmés III ${ }^{55}$. Devemos sublinhar o facto das capitais de distrito estarem providas de uma guarnição, pois de outro modo a zona seria facilmente tomada e o governador egípcio estaria desprovido de segurança. Segundo Singer, as tropas eram compostas tanto por egípcios como por asiáticos ${ }^{56}$. Talvez se torne mais claro se pensarmos que estas sociedades do Levante haviam sido dominadas, até então, pela sua aristocracia guerreira, que obviamente poderá ter sido uma mais valia para os egípcios, até pela própria experiência que tinham sobre o terreno ${ }^{57}$. Assim, dependendo da sua inserção geográfica, as guarnições estavam sob o controlo do governador ou de um príncipe local ${ }^{58}$. O facto de muitas vezes não se encontrar, sob registo arqueológico, uma construção que diríamos tipicamente egípcia, tem que ver com o facto de os egípcios aproveitarem, nesta cronologia, as estruturas já estabelecidas, na sua maioria, o que explica o claro aumento de cultura material entre a XVIII e XIX dinastia nestas regiões ${ }^{59}$. As guarnições tinham também como função realizar tarefas florestais pois, como sabemos, a madeira era um dos recursos mais apreciados ${ }^{60}$. Para além das guarnições existiam ainda as fortalezas, que tinham mais expressão nas áreas mais próximas do Egipto, como será o caso de Guezer, Lakish, Tjaru (Tell Hebua I) e Charuhen (Tell el-Ajjul). Estas tinham uma importância estratégica bem assente, pois são como linhas defensivas das próprias fronteiras do Egipto, de modo a controlar a movimentação das populações do Sinai e de Canaã. Sugere-se, aliás, que nestas houve erradicação da população e ocupação com egípcios ${ }^{61}$. As únicas fortalezas egípcias no Levante que poderão ter existido ficavam na zona do Líbano, ou em Biblos ou em Ullaza e datam do reinado de Tutmés III ${ }^{62}$. 


\section{c) Cidades portuárias}

Nas maiores zonas com arvoredo Tutmés III instalou bases em cidades junto ao mar. Fê-lo em Canãa e possivelmente no Líbano também, numa inteligente estratégia de controlar a linha costeira, pelas amplas vantagens que um domínio sobre essas cidades traria na política egípcia sobre a zona. Em primeiro lugar, permitia o controlo das passagens de pessoas e bens; em segundo, permitia a imposição de taxas alfandegárias; em terceiro, possibilitava o controlo de comunicações interestatais; e por último, eram bons sítios para criar pontos de armazenamento, não só de víveres, como de produtos a enviar para o Egipto, com o recurso à marinha. Este armazenamento servia os egípcios mobilizados, servia também para as oferendas a realizar aos templos egípcios criados na Síria-Palestina e, não menos importante, para futuro transporte daí para o Egipto ${ }^{63}$.

\section{d) A marinha}

Um dos maiores feitos de Tutmés III foi dotar o Egipto de uma marinha que pudesse ser útil na sua política imperial, uma marinha que tivesse expressão e se constituísse não só como um meio mercante, mas sobretudo como um meio de transporte. A marcha por terra era de aproximadamente $500 \mathrm{~km}$, compreendendo a deslocação de homens e objectos, sendo por isso difícil, lenta e cara ${ }^{64}$. A actuação no Levante tinha que ser rápida em caso de rebelião e, para além disso, este era o meio que permitia uma actuação de surpresa, ganhando vantagem táctica sobre o inimigo. Para isso, foi de grande importância a expansão da base marítima de Mênfis ou Auaris, Peru-nefer, que significa «boa viagem». O Egipto deixou de ser apenas um povo de navegação fluvial, para se tornar também num povo de navegação marítima. Alguns autores supõem mesmo que alguns cativos trazidos do Levante tenham desempenhado um importante papel no ensinamento destas navegações. Este tipo de navegação não tão só era mais barata, como mais eficaz, permitindo chegar rapidamente aos pontos de interesse. Por isso desenvolveram-se barcos maiores, capazes de transportar tropas e cavalos ${ }^{65}$. Mas tudo isso seria porém em vão se os egípcios não tivessem bases marítimas sob sua influência, como referimos na alínea anterior, de onde destacamos Gaza, Askelon, Tiro e Sidon ${ }^{66}$ e ainda Biblos e Ullaza ${ }^{67}$. Estas cidades costeiras foram, aliás, pontos-chave para a conquista militar do Levante, se não vejamos: Tutmés III transportou os seus soldados até Șumur e utilizou o porto desta para a conquista da Síria; usou portos como 
Ugarit como bases navais para o transporte militar e abastecimento das suas tropas; construíu em Biblos uma frota para a sua campanha ao Eufrates ${ }^{68}$.

A rota mediterrânica foi, em suma, uma potenciadora do sucesso militar do faraó, e uma das chaves para o controlo da Síria-Palestina.

\section{Conclusão}

O estudo do reinado de Tutmés III é de grande importância, não só pelos feitos militares que este faraó realizou mas também por ser, na verdade, um momento de viragem na história egípcia aos mais variados níveis. Pela primeira vez, o Egipto terá um afluir de riquezas nunca antes visto, um programa de construções sem paralelo, um aumento da burocracia exponencial ${ }^{69}$, uma centralização do poder do rei cada vez mais clara, uma importância crescente da classe militar, e um abundar de bens que enchiam o templo de Amon e dotavam de uma preciosa autoridade o seu clero. Arriscar-me-ia a dizer, face a isto, que Hatchepsut inovou no plano teórico e divino, quando se assume como filha do deus Amon, enquanto que o seu sobrinho-enteado inova numa esfera mais prática, pois leva além-fronteiras, como nunca se havia feito, o nome do seu pai Amon e a ele atribui as suas vitórias militares. Contudo, ambos convergem num ponto interessante: uma relação com o parentesco nunca antes vista, já que a memória de Tutmés I é sempre exaltada pelos dois.

Além disso, o rei egípcio passa a ser o protagonista no plano militar, assumindo-se como o grande chefe, guerreiro, imbatível, temido pelo resto do mundo. Daí que a importância da prática desportiva entre a elite, sobretudo na educação dos príncipes, fosse exaltada como nunca, pois agora esperava-se que o faraó fosse um autêntico líder militar. Como mencionámos, dá-se o início de um favorecimento das camadas militares sem precedente e que virá a desembocar, no seu expoente máximo, com o caso de Horemheb, que de escriba militar chegou a faraó, e depois na abertura da XIX dinastia com faraós que procedem desta classe.

Abriu-se também uma era de uma nova política externa e novas relações diplomáticas, em que o status quo internacional pautava-se pelo poderio militar e baseava-se, igualmente, nos interesses económico-comerciais. Além disso, a frequência, na documentação, do uso dos termos «maldito Retenu», «maldito Kuch» e «grande Hatti» podem ajudar a estabelecer o tipo de relações entre reinos, nem que o seja, simplesmente, no plano oficial. 
Fica pois claro que o domínio sobre Síria-Palestina teve, essencialmente, dois objectivos claros: o primeiro foi funcionar como zona tampão para evitar uma nova experiência de domínio estrangeiro sobre o seu território; o segundo pauta-se, claramente, pela disputa do Levante com o mundo do Próximo Oriente Antigo, sobretudo com o Mitanni, pois ambos os reinos ambicionavam ter sob o seu controlo esses pontos e rotas de comércio, fundamentais para assegurar a sua riqueza e glória. Não obstante, concluímos que nunca se procurou fazer desta área parte integrante do Egipto, tornando-a tão somente uma dependência, tal qual se fizera anteriormente com a Núbia. A administração destes territórios assumiu um carácter heterogéneo, já que as realidades políticas do Levante eram diversas ao longo da área explorada, pelo que pensamos tratar-se de uma administração fragmentária. Administração essa que estava nas mãos de oficiais do exército, e que depois de Tutmés III foram colocados como governadores nos três diferentes pólos administrativos, Gaza, Sumur e Kumidi. Aliado a isto, e de forma a controlar a população local, existiam guarnições egípcias ao longo do corredor sírio-palestino. No fundo, os Egípcios procuraram apoderar-se das zonas chave, cidades portuárias, pontos nevrálgicos de comércio, de grandes centros a partir dos quais fosse possível gerir a sua intervenção no meio do caos, e tiveram consigo sempre pequenas franjas do exército no terreno, destacadas para agir de imediato perante qualquer foco de rebelião. Para o funcionamento de todo este sistema, as redes de comunicação tiveram uma importância vital de modo a transmitir mensagens entre o Egipto e a sua dependência. Estava criada uma segunda anexação territorial egípcia, mais débil e mais problemática do que alguma vez fora a Núbia.

Em suma, o império que o Egipto criou não só possibilitou o reconhecimento do poder universal do faraó como a sua legitimação nos territórios conquistados $^{70}$. O Egipto conheceu, por todas as razões mencionadas, o erguer de um período que é conhecido como a sua época dourada, a qual tem na génese um dos maiores faraós de sempre, Menkheperré Djehutimés (Tutmés III).

\section{Notas}

(1) Autores como Flammini defendem a existência de um imperialismo na segunda Idade do Bronze Médio, confinado a entrepostos comerciais. Veja-se FLAMMINI, Megiddo y su relación con Egipto..., Relaciones de intercambio..., pp. 59-77. 
(2)

(3) CANHÃO, História de Sinuhe, A literatura egípcia do Império Médio, 1, pp. 77-132.

(4) CANHÃO, As Profecias de Neferti, A literatura egípcia do Império Médio, 2, p. 348.

(5) CARDOSO, Deslocamento e alteridade..., Phoînix, 16, p. 18.

(6) Ainda que aplicada à realidade mesopotâmica, veja-se, a propósito, BAHRANI, Race and Ethnicity..., World Archaeology, 38, pp. 48-59.

(7) Idem, p. 53.

(8) ARAÚJJ, Os Grandes Faraós do Antigo Egito, p. 91.

(9) Idem, pp. 117-118.

(10) MCDONALD, Egyptian interests in Western Asia..., AJBA p. 82.

(11) $O$ estudo dos escaravelhos presentes nas cidades do Delta ocupadas pelos Hicsos revela que a procedência destas populações é do Levante do Sul e não do Norte. Veja-se: BEN-TOR, Can scarabs argue for the origin of the Hyksos?, JAEI, 1, pp. 1-7.

(12) Idem, p. 3

(13) ZINGARELLI, La frontera sinaítica..., Trabajos y Comunicaciones 26-27, p. 23.

(14) BRÖNN, Foreign Rulers on the Nile, p. 21.

(15) PÉREZ-ACCINO, Egipto y el Corredor Sirio-Palestino..., Egypto y el exterior, p. 68.

(16) MARTÍNEZ BABÓN, Historia Militar de Egipto, p. 25.

(17) ARAÚJO, De Charuhen a Kadech..., Cadmo, 1, p. 122.

(18) Veja-se WILKINSON, The Power Configuration Sequence..., JWSR, 10, pp. 655-720.

(19) Cf. MARTíneZ BABÓN, Historia Militar de Egipto, p. 48.

(20) Cf. SINGER, Periferia "disputada" en el Levante..., Iberia, 9, pp. 7-19.

(21) GESTOSO, Las técnicas de la dominación imperial..., Aegyptus Antiqua, 10, p. 49.

(22) GABRIEL, Thutmose III..., p. 23.

(23) Ibidem

(24) Idem, p. 89.

(25) El Imperio Egipcio: inscripciones, ca. 1550-1300 a. C., ed. e trad. José Manuel Galán, p. 79. (Daqui em diante IEI). Redford sublinha a importância desta frase, defendendo que a preocupação de Tutmés é sincera, não se tratando de propaganda. Cf. REDFORD, Egypt, Canaan and Israel..., p. 156.

(26) A este propósito veja-se: WARD, From River to Sea..., JAEI, 2:3, pp. 42-49.

(27) GABRIEL, Thutmose III..., p. 42.

(28) Idem, p. 43.

(29) Idem, p. 55.

(30) IEI, p. 80.

(31) Para fazer esta divisão seguimos o esquema apresentado por Richard Gabriel.

(32) LALOUETTE, Thébes ou la Naissance d'un Empire, p. 300.

(33) SINGER, El Intercambio de Bienes..., p. 67. 
(34) Cf. SINGER, El Intercambio de Bienes..., p. 67 e p. 169.

(35) «Grâce au Commisaire du roi qui est dans Șumur (...)», EA, 68.

(36) SINGER, El Intercambio de Bienes..., p. 68.

(37) Cf. BRYAN, Administration in the reign of Thutmose III, Thutmose III: a new biography, p. 105.

(38) Veja-se Tomada de Ipu em: ARAÚJO, Mitos e Lendas: Antigo Egipto, pp. 215-218.

(39) Autobiografía de Djehuty, Proyecto Djehuty.

(40) Cf. LILYQUIST, The Gold Bowl Naming General Djehuty, Metropolitan Museum Journal, pp. 5-68; ver ainda LALOUETTE, Thèbes ou la Naissance d'un Empire, p. 338.

(41) «Os filhos e os irmãos dos chefes foram trazidos para ser guerreiros fiéis ao Egipto. E quanto a todos aqueles que morreram de entre estes chefes, sua majestade faria então que o seu filho ocupasse o seu trono", IEl, p. 88; Veja-se também EA 296.

(42) SINGER, El Intercambio de Bienes..., p. 70.

(43) IEl, p. 85.

(44) Há indícios de que o tributo de gado da Síria-Palestina para o Egipto fosse anterior, datável, pelo menos, do reinado de Hatchepsut. Veja-se: ALDRED, An unusual fragment ..., JNES, 15, pp. 150-152.

(45) SINGER, El Intercambio de Bienes..., p. 77.

(46) Entenda-se como tenda do rei nos acampamentos militares.

(47) IEl, p. 140.

(48) Para além do templo dedicado a Hathor em Biblos, «Minha majestade entregou 3 cidades do Alto Retenu: uma é Iniugas, outra é Yanoam e a outra é Herenkaru. O tributo da (sua) contribuição anual será para a fundação do templo de meu pai Amon", IEl, p. 99. Note-se que os Egípcios não obrigaram os autóctones a venerar os deuses egípcios, pelo contrário, até prestaram culto aos deuses locais.

(49) SIINGER, El Intercambio de Bienes..., p. 72. Veja-se EA 44.

(50) GESTOSO, Las técnicas de dominación imperial ..., Aegyptus Antiqua, 10, p. 52.

(51) SINGER, El Intercambio de Bienes..., p. 68.

(52) IEl, p. 122.

(53) Ver: KATZENSTEIN, Gaza in the Egyptian Texts..., JAOS, 102, pp. 111-113.

(54) Sobre Beth-Shean veja-se: MAZAR, The Egyptian Garrison Town ..., Egypt, Canaan and Israel, pp. 155-189;

(55) SINGER, El Intercambio de Bienes..., pp. 77-78.

(56) SINGER, El Intercambio de Bienes, p. 79.

(57) Veja-se sobre os maryannu: FIDANZA, Los maryannu, REE, 3, pp. 45-62; FIDANZA, Los maryannu, REE, 4, pp. 33-65;

(58) SINGER, El Intercambio de Bienes..., p. 75.

(59) MORRIS, The Architecture of Imperialism, pp. 141, 152, 153.

(60) IEl, p. 92.

(61) MORRIS, The Architecture of Imperialism, pp. 39-40. no reinado de Tutmés III as anteriores estruturas militares levantinas receberam tropas egípcias ou mantiveram a guarnição local embora ao serviço do Egipto. 
(62)

(63) MORRIS, The Architecture of Imperialism, pp. 138-139.

(64) GABRIEL, Thutmose III..., p. 55.

(65) Idem, p. 56

(66) SINGER, El Intercambio de Bienes..., p. 73.

(67) MORRIS, The Architecture of Imperialism, p. 156.

(68) GESTOSO, Las técnicas de dominación imperial..., Aegyptus Antiqua, 10, p. 51.

(69) Um indicador muito claro desta situação é o aumento do número de túmulos construídos para novos funcionários, que quadriplicou em relação às dinastias anteriores. Cf. GABRIEL, Thutmose III..., p. 8.

(70) GESTOSO, Las técnicas de la dominación imperial ..., Aegyptus Antiqua, 10, p. 55.

\section{Bibliografia}

\section{Fontes}

ARAÚJO, L. M., A Tomada de Ipu, Mitos e Lendas: Antigo Egipto, Lisboa: Livros\&Livros, 2005, pp. 215-218.

CANHÃO, T., A literatura egípcia do Império Médio: espelho de uma civilização, vol. 1 e 2, dissertação de doutoramento em História apresentada à Faculdade de Letras da Universidade de Lisboa, Lisboa, 2010, pp. 77-132. Publicada electronicamente em: http://hdl.handle.net/10451/2461

El Imperio Egipcio: inscripciones, ca. 1550-1300 a. C., ed. e trad. José Manuel Galán, Madrid: Trotta, 2002.

Inscripción funeraria de Djehuty, Proyecto Djehuty. [Consult. 12 Jun. 2012]. Disponível em: http://www.excavacionegipto.com/.

(Auto)biografía de Djehuty, Proyecto Djehuty. [Consult. 12 Jun. 2012]. Disponível em: http:// www.excavacionegipto.com/.

Les Lettres d'El'Amarna : correspondance diplomatique du pharaon, trad. de William L. Moran, Paris: Éd. du Cerf, 1987.

\section{Estudos}

ALDRED, C., An unusual fragment of the New Kingdom relief, Journal of Near Eastern Studies, vol. 15, $n^{\circ} 3$, 1956, pp. 150-152. [Consult. 24 Maio 2012]. Disponível em: http://www. istor.org/stable/542307.

ARAÚJO, L. M., De Charuhen a Kadech: Relações entre o Egipto do Império Novo e a Ásia, Cadmo 1, revista de História Antiga da Faculdade de Letras da Universidade de Lisboa, 1991.

ARAÚJO, L. M., Os Grandes Faraós do Antigo Egito: 30 Faraós, 30 Dinastias, Lisboa: Esfera dos Livros, 2011. 
BEN-TOR, D., Can Scarabs Argue for the Origin of the Hyksos?, Journal of Ancient Egyptian Interconnections, vol. 1, 2009, pp. 1-7. [Consult. 20 Abr. 2012]. Disponível em: https:// journals.uair.arizona.edu/index.php/jaei/article/view/4

BIETAK, M., Egypt and the Levant, The Egyptian World, ed. Toby Wilkinson, New York: Routledge, 2010.

BAHRANI, Z., Race and Ethnicity in Mesopotamian Antiquity, World Archaeology. Race, Racism and Archaeology, vol. 38, pp. 48-59, 2006. [Consult. 17 Out. 2011]. Disponível em: http:// www.jstor.org/pss/40023594.

BRYAN, B. M., The $18^{\text {th }}$ Dynasty before the Amarna Period (c. 1550-1352 b.C.), The Oxford History Ancient Egypt, ed. Ian Shaw, Oxford: Oxford University Press, 2003.

BRYAN, B. M., Administration in the reign of Thutmose III, Thutmose III: a new biography, ed. Eric Cline e David O'Connor, Ann Arbor: The University of Michigan Press, 2009.

BRÖNN, J. A., Foreign Rulers on the Nile: a reassessment of the cultural contribution of the Hyksos in Egypt, dissertação de mestrado em Culturas Antigas apresentada à Universidade de Stellenbosch, África do Sul, 2006. [Consult. 26 Abr. 2012] Disponível em: http://scholar. sun.ac.za/handle/10019.1/1899.

CARDOSO, C. F., Deslocamento e Alteridade: a associação da distância e da viagem com o estranho e o maravilhoso entre os Antigos Egípcios, Phoînix, vol. 16, 2010, p. 18. [Consult. 27 Abr. 2012]. Disponível em: http://www.revistaphoinix.com/phoinix20101/ artigo001 cirocardoso.pdf.

CARREIRA, J. N., O Egípcio, a Viagem e o Outro, Cadmo, 11, revista do Instituto Oriental da Universidade de Lisboa, Lisboa: Centro de História da Universidade de Lisboa, 2001, pp. 15-31.

EDGERTON, W. F., Ancient Egyptian Ships and Shipping, The American Journal of Semitic Languages and Literatures, vol. 39, $\mathrm{n}^{\circ} 2,1923$, pp. 109-135. [Consult. 25 Maio 2012] Disponivel em: http://www.jstor.org/stable/528485.

EXELL, K; NAUNTON, C., The administration, The Egyptian World, ed. Toby Wilkinson, New York: Routledge, 2010.

FIDANZA, V. P., Los maryannu: su inserción socio-política en los estados de Siria y Palestina durante el Período del Bronce Reciente, Revista de Estudios de Egiptología, n³, 1992, pp. 45-62.

FIDANZA, V. P., Los maryannu: su inserción socio-política en los estados de Siria y Palestina durante el Período del Bronce Reciente II, Revista de Estudios de Egiptología, nº 4, 1993, pp. 33-65.

FLAMMINI, R. C., Megiddo y su relación con Egipto durante el BM IIA, Relaciones de intercambio entre Egipto y el Mediterráneo Oriental (IV-I Milenio A.C.), $1^{\text {a }}$ ed., Buenos Aires: Biblos, 2001, pp. 59-77.

GABRIEL, R. A., Thutmose III: The military biography of Egypt's Greatest Warrior King, Virginia: Potomac Books, 2009.

GESTOSO, G. N., Las técnicas de la dominación imperial egipcia en Asia bajo Tuthmosis III: Propaganda y realidade, Aegyptus Antiqua, vol. 10, Centro de Estudios del Egipto y del Mediterraneo Oriental, Buenos Aires: 1999, pp. 49-60. Disponível em: http://independent. academia.edu/GracielaGestosoSinger/Papers/649538/Las tecnicas de la dominacion imperial egipcia en Asia bajo Tuthmosis III Propaganda y Realidad.

HORN, S. H., Scarabs from Schechem, Journal of Near Eastern Studies, vol. 21, n 1, 1962, pp. 1-14. [Consult. 24 Maio 2012] Disponível em: http://www.jstor.org/stable/543548.

KATZENSTEIN, H. J., Gaza in the Egyptian Texts of the New Kingdom, Journal of the American Oriental Society, vol. 102, $n^{\circ} 1,1982$, pp. 111-113. [Consult. 26 Abr. 2012]. Disponível em: http://www.jstor.org/stable/601117. 
KEMP, B. J., Old Kingdom, Middle Kingdom and Second Intermediate Period c. 2686-1552 BC, Ancient Egypt: A Social History, Cambridge: Cambridge University Press, 1987.

LALOUETTE, C., Thébes ou la Naissance d'un Empire, Paris: Flammarion, 1995.

LILYQUIST, C., The Gold Bowl Naming General Djehuty: A study of objects and early Egyptology, Metropolitian Museum Journal, vol. 23, 1988, pp. 5-68. [Consult. 23 Maio 2012]. Disponível em: http://jstor.org/stable/1512846.

LIVERANI, M., Prestige and Interest: International Relations in the Near East ca. 1600-1100 B.C., Padova: Sargon Srl, 1990.

MARTÍNEZ BABÓN, J., Historia Militar de Egipto durante la Dinastía XVIII, Barcelona: Fundació Arqueològica Clos, Museu Egipci, 2003.

MCDONALD, J., Egyptian Interests in Western Asia to the End of the Middle Kingdom: An Evaluation, Australian Journal of Biblical Archaeology, 1972, p. 82. [Consult. 26 Abr. 2012]. Disponível em: http://www.biblicalarchaeology.org.uk/pdf/ajba/01-5 072.pdf.

MANLEY, B., Atlas Historique de l'Égypte Ancienne. De Thébes à Alexandrie: la tumultueuse épopée des pharaons, Paris: Éditions Autrement- Collection Atlas/Mémoires, 1998.

MAZAR, A., The Egyptian Garrison Town at Beth-Shean, Egypt, Canaan and Israel: History, Imperialism, Ideology and Literature, Proceedings of a Conference at the University of Haifa 3-7 Maio 2009, ed. S. Bar, D. Kahn e J.J. Shirley, Boston: Brill, 2011, pp. 155-189.

MORET, A; DAVY, G., L'Empire Égyptien et le concert international, Des Clans aux Empires: l'organisation sociale chez les primitifs et dans l'Orient Ancien, Paris: La Renaissance du Livre, 1923, pp. 299-248.

MORRIS, E., The Architecture of Imperialism: Military bases and the evolution of the foreign policy in Egypt's New Kingdom, Boston: Brill, 2005.

MURNANE, W., Imperial Egypt and the Limits of Power, Amarna Diplomacy: the beginnings of international relations, ed. Raymond Cohen e Raymond Westbrook, Baltimore: The Johns Hopkings University Press, 2000, pp. 101-111.

O'CONNOR, D., New Kingdom and Third Intermediate Period, 1552-664 b. C., Ancient Egypt: A Social History, Cambridge: Cambridge University Press, 1987.

PATON, L. B., The Civilization of Canaan in the Fifteenth Century B.C., The Biblical World, vol. 20, nº 1, 1902, pp. 25-30. [Consult. 24 Maio 2012]. Disponível em: http://www.jstor.org/ stable/3137384

PÉREZ-ACCINO, J. R., Egipto y el Corredor Sirio-Palestino a comienzos de la dinastia XVIII: fissuras en el paradigma, Egipto y el Exterior: contactos e influencias, ed. Luis A. Garcia Moreno e Antonio Pérez Largacha, Alcalá: Universidad de Alcalá, 1997, pp. 67-85.

PÉREZ-ACCINO, J. R., Historia, ciência y paradigmas en los orígenes de la XVIII dinastia egípcia, Espacio, Tiempo y Forma, Serie II, $H^{a}$ Antigua, vol. 7, 1994, pp. 375-381.

REDFORD, D. B., Egypt, Canaan and Israel in Ancient Times, New Jersey: Princeton University Press, 1993.

SALES, J. C., Administração, Dicionário do Antigo Egipto, Lisboa: Editorial Caminho, 2001.

SALES, J. C., Ásia, Dicionário do Antigo Egipto, Lisboa: Editorial Caminho, 2001.

SASSON, J. M., Canaanite Maritime Involvement in the Second Millennium B.C., Journal of the American Oriental Society, vol. 86, $\mathrm{n}^{\circ}$ 2, 1966, pp. 126-138. [Consult. 24 Maio 2012]. Disponivel em: http://www.jstor.org/stable/596425.

SCHULMAN, A., Egyptian Representations of Horsemen and Riding in the New Kingdom, Journal of Near Eastern Studies, vol. 16, n 4, 1957, pp. 263-271. [Consult. 24 Maio 2012]. Disponível em: http://www.jstor.org/stable/542186. 
SHAW, I., Egypt and the Outside World, The Oxford History Ancient Egypt, ed. Ian Shaw, Oxford: Oxford University Press, 2003.

SINGER, G. G., Egipto y sus periferias en el Levante durante la dinastia XVIII, Cahiers Caribéens d'Egyptologie, $\mathrm{n}^{\circ}$ 11, Fevereiro-Março, 2008.

SINGER, G. G., Periferia "disputada" en el Levante durante la dinastia XVIII egípcia. Áreas Productivas y Estratégicas, Iberia, $n^{\circ}$ 9, 2006, pp. 7-19. Disponível em: http://scholar. google.pt/scholar?cluster $=2313537203988952415 \& \mathrm{hl}=$ pt-PT\&as $\mathrm{sdt}=0,5$

SINGER, G. G., El Intercambio de Bienes entre Egipto y Asia Anterior: Desde el reinado de Tuthmosis III hasta el de Akhenaton, Ancient Near East Monographs, Society of Biblical Literature, Centro de Estudios de Historia del Antiguo Oriente UCA, vol. 2, 2008.

SMITH, S. T., Ethnicity and Culture, The Egyptian World, ed. Toby Wilkinson, New York: Routledge, 2010.

SPALINGER, A., The Army, The Egyptian World, ed. Toby Wilkinson, New York: Routledge, 2010.

WARD, C., From River to Sea: evidence for Egyptian seafaring ships, Journal of Ancient Egyptian Interconnections, vol. 2, 2010, pp. 42-49.

WILKINSON, D., The Power Configuration Sequence of the Central World System 1500-700 BC, Journal of World-Systems Research, vol. 10, $\mathrm{n}^{\circ}$ 3, 2004, pp. 655-720.

WILKINSON, Auge y Caída del Antiguo Egipto, Barcelona: Debate, 2011, pp. 297-314.

WILSON, J. A., The Oath in Ancient Egypt, Journal of Near Eastern Studies, vol. 7, $n^{\circ}$ 3, Julho, 1948. [Consult. 26 Mar. 2012]. Disponível em: http://www.jstor.org/stable/542530 pp. 129-156.

ZINGARELLI, A., La frontera sinaítica del Egipto Antiguo, Trabajos y Comunicaciones, 26-27, Facultad de Humanidades y Ciencias de la Educación de la Universidad Nacional de La Plata, 2000-2001, pp. 11-43. [Consult. 26 Abr. 2012]. Disponível em: http://www.memoria. fahce.unlp.edu.ar/art revistas/pr.6/pr.6.pdf 